\title{
OS ASPECTOS CONTEMPORÂNEOS DA RESPONSABILIDADE CIVIL DO ESTADO: A TEORIA OBJETIVA E A ATUAÇÃO DO SUPREMO TRIBUNAL FEDERAL
}

\author{
Ícaro Moreira Ursine ${ }^{1}$ \\ Edimur Ferreira de Faria ${ }^{2}$
}

\section{RESUMO:}

A responsabilidade civil do Estado é um instituto social de reparação que evoluiu e se modificou com o tempo. Apesar de definida na Constituição da República, não é possível demonstrar a existência de unicidade em sua aplicação pelo Judiciário brasileiro, especialmente na jurisprudência firmada pelo Supremo Tribunal Federal. Para firmar esse entendimento, a presente pesquisa revisitou os períodos de irresponsabilidade, responsabilidade subjetiva e objetiva, apresentando os resquícios de cada fase no direito contemporâneo. Por meio da pesquisa bibliográfica busca-se deduzir se a hipótese de inexistência de unicidade é verificável e quais as consequências sociais que sua ausência pode trazer.

Palavras-chave: Responsabilidade civil do Estado; Responsabilidade objetiva; Jurisprudência constitucional; Teoria do risco administrativo; Teoria do risco integral

\section{THE CONTEMPORARY ASPECTS OF CIVIL RESPONSIBILITY OF THE STATE: THE OBJECTIVE THEORY AND THE ACTION OF THE SUPREME COURT}

\begin{abstract}
:
The civil liability of the state is a social institute of reparation that has changed over time. Although defined in the Constitution of the Republic, it's impossible to demonstrate the existence of uniqueness in its application by the Brazilian Judiciary, especially in the jurisprudence signed by the Supreme Court. In order to establish this understanding, the present research revisited the periods of irresponsibility, subjective and objective responsibility, presenting the remnants of each phase in contemporary law. Through the bibliographical research it is sought to deduce if the hypothesis of non-uniqueness is verifiable and what social consequences its absence can bring.
\end{abstract}

Keywords: Civil liability of the State; Objective responsibility; Constitutional jurisprudence; Theory of administrative risk; Theory of integral risk

\section{INTRODUÇÃO}

A reparação é conduta racional do ser humano, ligado à sua adaptação para a vida em

\footnotetext{
${ }^{1}$ Advogado, mestrando em Direito Público com foco no Direito Econômico.

2 Doutor em Direito pela UFMG e professor do Programa de Pós-graduação em Direito da Pontifícia Universidade Católica de Minas Gerais.
} 
sociedade. As ponderações e valores sobre esse instituto evoluem e variam de acordo com cada cultura. Para alcançar a reparação, as sociedades admitiram diversas formas de pagamento, ouro, trabalho, retribuição em igual proporção, perdão da dívida e até partes do corpo foram meio para satisfação do direito do credor, utilizados durante vários séculos.

A responsabilidade civil é resultado da evolução jurídico/normativa constantemente aprimorada na sociedade. Primeiramente a responsabilidade foi disciplinada entre os civis, com regras e princípios tradicionais. As transformações sociais levaram ao fortalecimento do Estado que assumiu papel relevante na complexa relação entre os cidadãos. Posteriormente, observou-se que a interação comum entre o Estado e o cidadão era juridicamente desequilibrada o que poderia gerar prejuízos para a parte mais vulnerável, o cidadão. $\mathrm{Na}$ tentativa de superar essa vulnerabilidade, o tema da responsabilidade civil saiu, em parte expressiva, do âmbito do Direito Civil e passou a ser disciplinada pelo Direito Público.

Objetiva-se, nesse artigo, verificar se a jurisprudência constitucional tem uniformidade em relação a responsabilidade civil do Estado em conformidade com o disposto no art. 37, § 6 da Constituição da República de 1988 e no art. 43 do Código Civil de 2002. A jurisprudência constitucional baseia todas as decisões que serão tomadas nos tribunais e juízos inferiores, principalmente com o advento do novo Código de Processo Civil (Lei n'13.105/2015). O Supremo Tribunal Federal (STF), guardião da Constituição, tem por pressuposto o monopólio em relação a construção da jurisprudência constitucional e tem o dever de transmitir segurança decisional. Por consequência, compete ao Judiciário, criar o arcabouço de decisões que observe as normas e garantias asseguradas pela Constituição.

A aplicação da responsabilidade civil do Estado é feita de maneira coerente considerando o Sistema Jurídico brasileiro? A hipótese prevista é que não há clareza na aplicação do instituto da responsabilidade civil considerando as decisões divergentes do Supremo Tribunal Federal. A temática é importante para demonstrar, por meio da pesquisa adotada, que não há ordenação lógica decisional sobre a responsabilidade civil do Estado, tendo-se em vista que elas podem variar de acordo com o contexto social da época, com a composição colegiada do órgão julgador e com o caso concreto, mesmo que a base jurídica para a definição da responsabilidade seja a mesma.

A metodologia empregada é a bibliográfica analítica que buscará envolver posicionamentos doutrinários e jurisprudenciais, e ainda as disposições legais, para se deduzir a validade da hipótese ligada ao problema de coerência decisional. A pesquisa jurisprudencial 
no Supremo Tribunal Federal foi resultante das palavras-chave: Responsabilidade civil do Estado; Responsabilidade Objetiva do Estado; Teoria do Risco Administrativo; Teoria do Risco Integral; Responsabilidade civil do Estado por Omissão, dentre outras conexas. Ressalte-se que algumas decisões serão citadas por meio de nota de roda pé explicativa para o conhecimento do leitor.

Para aprimorar o texto, buscou-se desenvolver a ideia de responsabilidade desde sua origem, destacando-se a necessidade do instituto para a defesa do cidadão e finalizando com a problemática da insegurança decisional do Supremo Tribunal Federal. A conclusão confirma a hipótese apresentada. Apesar de importante, a responsabilidade civil do Estado é cercada de incertezas, o resultado depende da condição política, relevância social e impacto econômico no momento da decisão. Tendo em vista essas considerações, passa-se a analisar o Estado sob o prisma da ficção jurídica.

\section{O ESTADO SOB O PRISMA DA FICÇÃO JURÍDICA}

A existência de ficção jurídica para atribuir ao Estado responsabilidade é essencial na contemporaneidade. As primeiras reflexões de Hobbes sobre a existência do Estado trazem à tona a ideia de manifestação de cada cidadão na formação do ente maior que os indivíduos. Hobbes (2016, p. 9) salienta: "Porque pela arte é criado aquele grande Leviatã a que se chama Estado, ou Cidade [...], que não é senão um homem artificial, embora de maior estatura e força do que o homem natural, para cuja proteção e defesa foi projetado. "

Os contratualistas clássicos como Rousseau, Hobbes e Montesquieu utilizaram-se do Direito Natural para justificar a existência do Estado soberano. Os autores refletiram sobre a necessidade e as possibilidades para que o Estado se posicione acima dos interesses do particular, no entanto, limitado na complexa estrutura sistêmica de Montesquieu. Cabe ressaltar que a divisão das funções do Estado é nitidamente mais antiga do que a doutrina explicitada pelos autores contratualistas. Já na Grécia antiga, a obra de Aristóteles trazia o esboço sobre a atuação do Estado por meio de poderes repartidos. (COUCEIRO, 2016)

Apesar de buscarem os fundamentos básicos da existência do Estado, a noção de personalidade jurídica, somente, foi percebida posteriormente. Segundo Dalari, a necessidade de fixar o Estado no plano jurídico nasce na Alemanha. A personificação do Estado se mostra como o principal avanço coletivo em relação a possibilidade de limitação jurídica das ações e 
questões envolvendo o Estado. Assim, para o controle estatal, estabelece-se critérios mais práticos do que os anteriores.

O Leviatã é submetido ao conjunto de regras, direitos e obrigações, e recebe personalidade própria, distinta de seus membros. O pensamento de incorporação do Estado pelo sujeito específico, normalmente monárquico, deixa espaço para definiçãa e criação no Ordenamento Jurídico, L'État c'est moi é que se considerava o Rei Luís XIV da França, perde seu significado para as democracias. (DALARI, 1998, p. 46)

Em síntese, existem duas correntes principais no tocante a ideia de personalidade jurídica. A primeira corrente é correlacionada a existência fictícia. Savigny afirma, segundo Dalari (1998), que o sujeito real é aquele que tem vontade e consciência individualizada, independente de outro sujeito. A outra corrente está baseada no campo da realidade. Alguns autores explicam a personalidade do Estado como organicismo biológico, o ser biológico que emana vontades, dentre eles estão Gerber e Gierke. Inclui nessa vertente a ideia de organismo moral com existência própria que depende de seus órgãos para interagir independente da vontade dos próprios membros e cidadãos.

As duas correntes, a realista e a ficcionista, coadunam-se na medida em que distanciam o Estado da vontade de seus participantes e o posicionam como ser autônomo e responsável por suas atitudes. A base para a responsabilização do Estado está justamente na possibilidade científica de limitação das ações do "ser" poderoso por si só. Perceber as consequências das ações do Estado é efeito do trabalho científico pautado na separação concreta do cidadão e da entidade administradora. Dessa forma, a problemática trazida pela formação do Estado é superada pela eleição de mecanismos coerentes de controle que afastam as pessoas físicas envolvidas e apresentam o "ser" próprio para se responsabilizar.

A responsabilidade civil do Estado está conectada ao reconhecimento no ordenamento jurídico de personalidade jurídica independente das ações das pessoas físicas que dão concretude a essas atitudes. Como será demonstrado, a irresponsabilidade por danos advindos do Estado tem relação com a existência indissociável, até então, entre a figura do monarca (soberano) e o Estado. Destarte, a personalidade jurídica dá margem aos pleitos de indenização que são tão comuns no dia a dia do povo brasileiro.

Diante da possibilidade de responsabilização do Estado, tendo em vista sua personalidade jurídica, os doutrinadores passaram a sistematizar o tema. Basicamente dividem a responsabilidade civil do Estado levando em consideração os momentos de 
irresponsabilidade total, o de responsabilidade subjetiva e da objetiva. Atualmente o Brasil está predominantemente utilizando a teoria da responsabilidade objetiva em observância a comando expresso da Constituição da República com a seguinte redação:

Art. $37 \S 6^{\circ}$ As pessoas jurídicas de direito público e as de direito privado prestadoras
de serviços públicos responderão pelos danos que seus agentes, nessa qualidade,
causarem a terceiros, assegurado o direito de regresso contra o responsável nos
casos de dolo ou culpa. (BRASIL, 1988)

Registre-se que a sintonia entre a Constituição da República e o Código Civil só foi observada em 2002 com a promulgação da Lei no 10.406, de 10.01.2002. O Código disciplina no art. 43 a responsabilidade objetiva das pessoas jurídicas de direito público interno em coerência sistêmica com o instituto trabalhado, entretanto, em relação às empresas privadas prestadoras de serviços públicos. (BRASIL, 2002)

\subsection{Irresponsabilidade}

A fase de irresponsabilidade do Estado perdurou até o século XIX e foi construída, principalmente na teoria divina dos reis. As condutas dos monarcas eram emanadas de Deus, por isso divinas. Razão, por que não faziam mal a ninguém. Ressalte-se que alguns poucos Estados continuaram irresponsáveis até o século XX, entre os quais os Estados Unidos e a Inglaterra, 1946 e 1947 respectivamente. A fase da irresponsabilidade perdurou por mais tempo na sociedade e ainda pode ser percebida indiretamente na modernidade.

A maioria dos doutrinadores nacionais afirmam que a irresponsabilidade do Estado não foi acolhida pelo Brasil. No entanto, Nascimento (1995) menciona a inexistência de responsabilidade pela intangibilidade do Rei e dos mandatários durante a fase de colonização das terras tupiniquins. Ademais, o autor assinala a existência das Ordenações Portuguesas como regra vigente no Brasil e salienta que, em especial as Ordenações Filipinas, foram baseadas na máxima "o rei não erra".

Esteves (2003) também apresenta a possível fase de irresponsabilidade civil no Brasil colonial. O que refutaria boa parte da doutrina que mantém o entendimento quanto a inexistência de irresponsabilidade.

Para exemplificar, o livro quinto das Ordenações Afonsinas retrata em seus títulos comandos e consequências para os súditos do Rei. O primeiro deles é direcionado aos hereges que afrontam a justa posição do Rei e dos Príncipes que são enviados por Deus para governar o povo. Nas ordenações, os títulos, temas de cada enunciado, acabam por demonstrar que o 
súdito não teria a possibilidade de encontrar reparação frente as sempre acertadas atitudes do Rei. (HEITOR, 2016)

A irresponsabilidade é decorrente da ideia de soberania do governante, normalmente o monarca, e do Estado sobre o cidadão. Mesmo após a Revolução Francesa, de 1789, com a adoção da tripartição dos poderes, a população era relutante em admitir a interferência do juiz nas funções do Legislativo, exercidas pelos representantes do povo, fato que manteve em certa medida a irresponsabilidade estatal em desfavor dos cidadãos. Registre-se que a França não foi a primeira a instituir o Estado de direito com divisão de poderes. Os Estados Unidos a antecederam em 1787. (SILVA, 2012)

\subsection{Da irresponsabilidade à responsabilidade estatal}

A irresponsabilidade do Estado foi se tornando insustentável com o passar do tempo. Para trazer segurança jurídica buscou-se a situação ideal em que o Estado se submetesse às próprias leis. Nesse contexto, o primeiro passo para a superação da irresponsabilidade do Estado é a previsão legal de situações específicas em que o Estado é responsabilizado por danos decorrentes de conduta de seus agentes, em desconformidade com o Direito posto. A legalidade, nesse sentido, é apresentada como situação de início da suplantação da irresponsabilidade estatal, que perdurou por séculos. (MELLO, 2014)

$\mathrm{Na}$ análise contemporânea, é necessário ressaltar que a irresponsabilidade do Estado pode decorrer da impossibilidade da perquirição da reparação nos órgãos competentes. $\mathrm{O}$ cidadão sem amparo para acesso ao Judiciário, fica sem ação em relação à reparação civil. Dessa forma, o Estado, além do dever de manter previsão legal adequada aos anseios sociais quanto à responsabilização, deve manter o aparato judicial coerente com essa sistemática.

O Estado não deve ser formalmente responsável, e materialmente irresponsável por seus atos. Dessa forma, o Estado de Direito deve prever as hipóteses de responsabilidade, os ritos processuais e o acesso ao Judiciário de maneira simplificada. A simplicidade decorre da posição de desvantagem do cidadão em situação de conflito com o Estado. Para equilibrar a relação jurídica, o ordenamento jurídico prescreve meios para facilitar a ação do cidadão. Entre os meios cita-se o reconhecimento da responsabilidade objetiva do Estado. Nessa hipótese, apenas o dano e o nexo de causalidade devem ser apresentados.

Afastar o cidadão da oportunidade de alcançar a justa reparação é forma de encriptação do comando constitucional de não lesionar que é imposto ao Estado. Esse ato de 
esconder garantias e desviar a atenção do povo está entre as atitudes ardilosas utilizadas por alguns governantes com o intuito de negar à população o efetivo acesso aos direitos e garantias fundamentais. As garantias contra esses abusos estão previstas na Constituição da República de 1988, que devem ser realizadas nos parâmetros aceitáveis, universais e justos, tendo-se em vista a insignificância do cidadão em face do Estado. A inobservância de garantias constitucionais dá margem ao Ente Público de, por meio de artifícios ilegais, eximirse de responsabilidade, em desfavor do cidadão que, sem ação, sofre as consequências da violação de seus direitos resultado do descumprimento da Constituição da República.

\subsection{Descumprimento parcial ou cumprimento tardio de obrigação reconhecida pelo Judiciário}

Há situações em que o Estado, principalmente os Estados-membros e os Municípios, embora condenados judicialmente, não cumprem as decisões em tempo hábil, configurando hipótese de descumprimento da Constituição e da legislação infraconstitucional. A propósito, traz-se a título de exemplo ilustrativo, o art. 100 da Constituição da República. O citado artigo prescreve que depois do trânsito em julgado e da liquidação da sentença, o Presidente do respectivo Tribunal encaminhará até o dia $1^{\circ}$ de julho, ao órgão fazendário, a requisição do precatório, para que o valor seja consignado no orçamento anual do exercício subsequente, devendo o pagamento ser efetuado no exercício, observando-se a ordem cronológica da apresentação dos precatórios. Esse prazo de até um ano e meio para a quitação dos mesmos não é cumprido pela maioria dos Entes federados. Justificam-se essa morosidade, alegando a falta de recursos financeiros, fato que pode servir de subterfúgio para o não pagamento das indenizações devidas, no prazo estabelecido pela Constituição, o que leva, ou pode levar, a situação contemporânea de irresponsabilidade do Estado. (BRASIL, 1988)

Indaga-se sobre os acordos realizados entre a Administração Pública e os credores dos precatórios, situação em que o cidadão renuncia até $40 \%$ de seu precatório deixando de receber grande parcela do seu montante, conquistado em longa e onerosa batalha judicial. $\mathrm{O}$ deságio prejudica o direito concreto na medida que afasta o cumprimento regular das obrigações do Estado. A prática do deságio como padrão para os precatórios leva novamente a encriptação, ocultação, artifícios que configuram mitigação ou até a irresponsabilidade do Estado. (SÃO PAULO, 2015)

Os estudos sobre a encriptação do direito e do povo oculto são sistematizados por 
Restrepo (2011). Segundo ele, as estruturas sociais e estatais podem assegurar que os direitos dos cidadãos não sejam exercidos de maneira correta, levando a encriptação do querer social. As observações trazidas pelo autor são válidas para criar a leitura crítica sobre alguns institutos que se perpetuam no Brasil sem explicação aparente e que escondem a violação do direito do cidadão.

\subsection{Responsabilidade pessoal do agente público}

A responsabilidade pessoal do agente público foi o momento de transição para a responsabilidade subjetiva do Estado, por culpa anônima. Cabe lembrar que a responsabilidade da pessoa é decorrente da visão civilista de culpa ou dolo. É o que se constata na Constituição brasileira de 1824, que nos artigos 133, 143, 156 e 179, cuida de fato, nexo e dano, nos casos de dolo ou culpa. (BRASIL, 1824)

O momento de transição é visto na Constituição de 1824 no tocante aos artigos 99 e 129, que ressaltam que o Imperador é sagrado e inviolável, insusceptível de responsabilização, bem como a Regência e o Regente. Verifica-se que os artigos citados trazem a coexistência da irresponsabilidade do Governante e responsabilidade dos agentes individualmente considerados. (BRASIL, 1824)

$\mathrm{Na}$ análise contemporânea, a responsabilidade pessoal do agente público não foi abandonada no Direito brasileiro. O objetivo dessa manutenção é evitar que o agente seja inconsequente e utilize a máquina pública com fins diversos do interesse público. Nessa perspectiva, ressalte-se a evolução do combate à corrupção experimentada pelo Brasil nos últimos anos. Dentre as diversas operações, a mais proeminente denominada "Lava-Jato", vem alcançando os diversos níveis de corrupção. A operação alcançou o setor público nas pessoas ocupantes de cargos dos primeiros escalões do Executivo, de parlamentares e assessores do Legislativo, dos Entes Federados, de diretores de empresas estatais e o setor privado, como as empresas privadas, empresários e altos executivos corruptores, que efetivamente contaminam a estrutura política do Brasil.

A responsabilidade do agente é prerrogativa do Estado de acordo com a jurisprudência constitucional e não pode ser invocada pelo particular. Assim, assegura-se o direito do cidadão em buscar a responsabilidade do Estado. ${ }^{3}$

\footnotetext{
${ }^{3}$ Jurisprudência "direito de regresso": RE 228.977, Rel. Min. Néri da Silveira, DJ 12.4.2002; RTF 266.862.3,
} 


\section{A RESPONSABILIDADE SUBJETIVA E A UTILIZAÇÃO DA CULPA}

O instituto da culpa é tipicamente estruturado na esfera civil e, apesar disso, ainda tem aplicação na jurisprudência constitucional no tocante à responsabilidade estatal. Efetivamente não é possível falar-se em superação das antigas fases da responsabilidade do Estado, pois todas ainda mantêm ligação com o moderno Direito. Para compreender o desenvolvimento da responsabilidade, cabe, então, refletir sobre o instituto da culpa civil.

\subsection{O instituto da culpa civil}

A culpa no Ordenamento Jurídico é mais do que o sentimento sob a ótica freudiana. O instituto da culpa é marco importante para a sociedade, pois delimita a responsabilidade do agente público. Ela é o resultado moral ou jurídico de determinada ação e da consequência daquela ação. O peso social dado às especificidades da culpa fará com que a punição para o agente público seja mais branda ou não, considerando que os valores sociais estão intimamente ligados a atribuição de peso à culpa propriamente dita.

A responsabilidade convencional necessita da culpa para ser aplicada. Nesse sentido, as culturas antigas já aplicavam a lei da reciprocidade, conhecida como a lei de talião. Os antigos ensinamentos de Deus ao povo hebreu foram imortalizados no Torá, que traz regras sociais inestimáveis que, se constatada culpa, geram consequências severas. O livro Shemot / Êxodo descreve situações de culpa e as consequências que ela trará: “[...], mas se resultar dano, então darás vida por vida, olho por olho, dente por dente, mão por mão, pé por pé, queimadura por queimadura, ferida por ferida, golpe por golpe. [...]” (Shemot In Torah, 2016)

A culpa é a "violação de dever jurídico de modo a causar dano a outrem". No espectro da culpa existem várias faixas de ação expressas em dolo, culpa por omissão, escolha e imprudência. O instituto da culpa também se divide em contratual ou extracontratual, significa dizer que a relação jurídica entre os sujeitos se estabelece por contrato prévio, também conhecido como responsabilidade obrigacional, ou pela ação, que é gatilho para a nova relação jurídica sem a necessidade de prévio acordo. (GUIMARÃES, 2009, p. 250)

Discute-se sobre a apropriação da culpa no âmbito do Direito Público, pela ligação

Rel. Min. Cármen Lúcia, Segunda Turma, DJ 26.08.2009; ARE 908331 RS. Rel. Min. Dias Toffoli. DJ 15.03.2016. (BRASIL, 2017) 
direta e típica ao Direito Civil. A utilização do instituto da culpa civil no âmbito das pessoas jurídicas e principalmente no Direito Administrativo é superficial e passa por dificuldades. (NASCIMENTO, 1995)

\subsection{Responsabilidade subjetiva do Estado}

De acordo com Di Pietro (2014), inicialmente adotou-se a teoria civilista para a responsabilização do Estado, o que acabou fracassando devido aos aspectos peculiares da culpa e sua aplicação para as pessoas jurídicas.

Faria (2015) aponta o caso que marca o rompimento com o paradigma da responsabilidade pautada na teoria puramente civilista. Trata-se do caso Agnès Blanco ocorrido na França no ano de 1873 e deu ensejo ao processo no âmbito do Direito Público para apurar a responsabilidade da empresa estatal sobre o acidente.

Nesse viés, a verificação da culpa passa a ser vislumbrada na falta do serviço, sem buscar a identidade do agente envolvido, o que foi definido como culpa anônima da Administração Pública. Contemporaneamente, não há o abandono completo dessa vertente de subjetividade em relação às omissões do Estado. Os julgados constitucionais salientam que a responsabilidade do Estado no caso de inação é subjetiva e depende, em alguns casos, de conduta reiterada para se configurar. ${ }^{4}$

Outros julgados dão visibilidade à responsabilidade objetiva mesmo em casos de omissão. A chamada omissão específica leva em conta algumas condutas que são presumidamente verificáveis, em consonância com o risco administrativo no caso concreto. ${ }^{5}$ Apesar de ser mais coerente com o Ordenamento Jurídico, a demonstração da não conduta do Estado é difícil para o cidadão, fator que pode inviabilizar a reparação civil. Entretanto, a doutrina majoritária ainda sustenta a responsabilidade civil subjetiva do Estado nos casos de condutas omissivas. Entre os autores filiados a essa corrente de pensamento cita-se Dias (2004).

\footnotetext{
${ }^{4}$ Jurisprudência "responsabilidade subjetiva": AI 850063 MG. Rel. Min. Rosa Weber. DJ 10.09.2013; ARE 684736 CE. Rel. Min. Rosa Weber. DJ 20.08.2013; RE 585007 DF. Rel. Min. Ricardo Lewandowski. DJ 05.05.2009; RE 603342 PE. Rel. Min. Ricardo Lewandowski. DJ 02.12.2010. (BRASIL, 2017)

5 Jurisprudência "responsabilidade objetiva": RE 677139 PR. Rel. Min. Gilmar Mendes. DJ 20.10.2015; ARE 813433 RJ. Rel. Min. Rosa Weber. DJ 14.10.2014; RE 692332 PB. Rel. Min. Teori Zavasck. DJ 06.08.2013; RE 677283 PB. Rel. Min. Gilmar Mendes. DJ 17.04.2012; RE 594902 DF. Rel. Min. Cármen Lúcia. DJ 09.11.2010; RE 607771 SC. Rel. Min. Eros Grau. DJ 20.04.2010; RE 573595 RS. Rel. Min. Eros Grau. DJ 24.06.2008. (BRASIL, 2017)
} 


\subsection{O aspecto subjetivo e o Estado}

Apesar de existir doutrina tendente ao pensamento publicista em relação à responsabilidade do Estado, muitas vezes a jurisprudência resvala em questões de ordem subjetiva tipicamente civis para justificar e basilar as decisões. O elemento subjetivo tem como cerne a culpa e depende do sujeito para ser verificada. A culpa normalmente se liga diretamente ao agente público e a prova de tal conduta ou omissão é complexa e dispendiosa para o cidadão prejudicado.

A título de análise, apresenta-se a problemática envolvendo o Estado e a verificação de culpa em suas ações. A complexa relação entre o terceirizado e a Administração Pública perpassa a teoria subjetiva em meio ao comando constitucional de responsabilidade objetiva, art. $37 \S 6$ da Constituição da República. A responsabilidade subsidiária do Ente público por débitos trabalhistas decorrente da terceirização é o típico problema da demonstração de culpa que o trabalhador deverá assumir.

A jurisprudência constitucional admite a responsabilidade da Administração Pública no caso de culpa in elegendo ou in vigilando ${ }^{6}$, quando o Estado deixa de fiscalizar a empresa prestadora do serviço, terceirizada. Cumpre salientar que a Constituição não prevê a responsabilidade subsidiária subjetiva para qualquer Ente federativo. Outrossim, a responsabilidade subsidiária subjetiva deixa o cidadão, que trabalha para o Estado em regime de terceirização, desguarnecido de proteção objetiva, mais fácil de ser alcançada.

Nessa mesma ideia de culpa, fala-se em culpa publicizada ${ }^{7}$ que é associada à falta do serviço. O Min. Carlos Velloso, na formação da jurisprudência constitucional, ventila a ideia da teoria subjetiva para verificar a responsabilidade do Estado quando ele é omisso. Dessa maneira, o julgador adverte que se deve demonstrar culpa por negligência, imperícia ou imprudência para concretização do dano causado pelo Estado.

Indaga-se sobre a possibilidade de verificação de culpa no contexto constitucional de 1988. É decorrência lógica do art. $37 \S 6^{\circ}$ que o dano deve ser cometido por agente público, o que traz a necessidade de coadunar o ato ao dano pelo nexo de causalidade. Assim, não há a

\footnotetext{
6 Jurisprudência "responsabilidade subsidiária do Estado na terceirização": RCL 12634 RO. Rel. Min. Roberto Barroso. DJ 22.09.2015; Rcl 15512 AM. Rel Min. Rosa Weber. DJ 15.03.2016; RCL 21956 PE. Rel. Min. Edson Fachin. DJ 01.03.2016; RCL 13703 DF. Rel. Min. Rosa Weber. 15.12.2015. (BRASIL, 2017)

7 Jurisprudência "culpa publicizada": RE 179147, Rel. Min. Carlos Velloso. DJ 27.02.1998; RE 372472 RN. Rel. Min. Carlos Velloso. DJ 04.11.2003; RE 369820 RS. Rel. Min. Carlos Velloso. DJ 04.11.2003; RE 179147 SP. Rel. Min. Carlos Velloso. DJ 12.12.1997. (BRASIL, 2017)
} 
obrigatoriedade de demonstrar dolo ou culpa em qualquer caso, importando apenas a conduta em si, seja ela de ação ou de inação.

A subjetividade está associada apenas ao funcionário público quando ele é confrontado pelo Estado. A utilização de preceitos de culpa para elidir a responsabilidade estatal pode estar associada ao encobrimento de constantes violações dos direitos do cidadão em face da sistemática indigna de governo.

\section{RESPONSABILIDADE OBJETIVA DO ESTADO APLICADA}

A responsabilidade objetiva do Estado é circunscrita de divergências no tocante a aplicação prática no Supremo Tribunal Federal. A origem desse instituto é decorrente da dificuldade de associar a culpa, subjetividade, ao Estado. O Min. Celso de Mello salienta os pressupostos da responsabilidade da Administração:

Os elementos que compõem a estrutura e delineiam o perfil da responsabilidade civil
objetiva do Poder Público compreendem (a) a alteridade do dano, (b) a
causalidade material entre o eventus damni e o comportamento positivo (ação) ou
negativo (omissão) do agente público, (c) a oficialidade da atividade causal e
lesiva imputável a agente do Poder Público que tenha, nessa específica condição,
incidido em conduta comissiva ou omissiva, independentemente da licitude, ou não,
do comportamento funcional e (d) a ausência de causa excludente da
responsabilidade estatal. (BRASIL, 2012, grifo nosso)

A discussão sobre a licitude ou ilicitude das ações do Estado não deve ser suportada no tocante à responsabilidade objetiva. O dano causado pela ação lícita deve ser indenizado da mesma forma. Não é possível desconsiderar a responsabilidade do Estado com pretexto de licitude. No entanto, ela poderia ser considerada na dosimetria do valor da indenização.

A inversão do ônus da $\operatorname{prova}^{8}$ e a admissão de excludentes é ventilada no Supremo Tribunal Federal em algumas questões da teoria objetiva de responsabilidade. Nesse contexto, sublinha-se as ponderações de Carlos Silva em seus estudos que aponta ocultação da culpa no aspecto objetivo, o que levaria a aplicação de uma teoria subjetiva oculta no Ordenamento Jurídico pátrio. (SILVA, 2012).

A demonstração de inexistência de culpa por parte do Estado resvala tanto a questão processual de admissão do contraditório e da ampla defesa, quanto à questão de subjetividade das condutas do Estado. Por consequência, a inversão se torna perigosa na medida em que dá

\footnotetext{
${ }^{8}$ Durante o plenário em vídeo, o Relator Luiz Fux fala em inversão do ônus da prova. (BRASIL, 2016b) Relativo a jurisprudência constitucional: RE 841526 RS. Rel. Min. Luiz Fux. DJ 30.03.2016.
} 
margem a não responsabilização do Estado por danos quando se alega outras excludentes.

A evolução da responsabilidade estatal levou a objetivação do instituto. Nesse contexto, adotou-se a formulação pautada na igualdade entre os cidadãos em que os danos causados ao indivíduo seriam repartidos para toda a sociedade. Assim as teorias do risco foram desenvolvidas para balancear a responsabilidade objetiva do Estado. Os riscos se dividem em administrativo e integral que em síntese admitem ou não as cláusulas excludentes do nexo de causalidade. A tentativa básica do risco administrativo é evitar a má conduta do indivíduo, que poderia valer-se do risco integral para alcançar a indenização sem amparo jurídico. (ESTEVES, 2003)

\subsection{Risco administrativo}

A vertente do risco administrativo está relacionada ao ato lesivo e injusto causado pela Administração Pública. Não há a perquirição de culpa no tocante aos atos da Administração, bastando somente na lesão e no nexo de causalidade. Esse é o raciocínio predominante no Direito brasileiro, por conseguinte a jurisprudência vem reforçando a existência e aplicação da tese em muitos julgados. (MEIRELLES, 2010)

O risco administrativo ${ }^{9}$ possibilita afastar ou verificar a existência de responsabilidade pela análise do caso concreto. Busca-se dessa forma, estabelecer a argumentação lógica de fatos e danos, e para além disso, abre-se a possibilidade de demolição do alegado na presença de excludentes de responsabilidade. A ação singular da vítima, a força maior e o caso fortuito seriam formas de romper o nexo de causalidade. A jurisprudência, sobre o risco administrativo apresentada em nota de rodapé, lembram das constantes violações de direitos pela omissão e que seria inviável admitir teorias que facilitassem a responsabilização por omissão.

A jurisprudência constitucional traça o parâmetro de virtude aristotélica. O meiotermo, nem muita responsabilização do Estado, nem pouca. O pensamento que mais se aproximaria dessa virtude é o do risco administrativo. Não quer isso dizer que os ideais de

\footnotetext{
9 Jurisprudência “ adoção do risco administrativo": RE 234010 RJ. Rel. Min. Carlos Velloso. DJ 23.08.2002; RE 603626 MS. Rel. Min. Celso de Mello. DJ. 15.05.2012; ARE 655277 MG. Rel. Min. Celso de Mello. DJ 24.04.2012; AI 577908 GO. Rel. Min. Gilmar Mendes. DJ 30.09.2008; RE 495740 DF. Rel. Min. Celso de Mello. DJ 15.04.2008; RE 505393 PE. Rel. Min. Sepúlveda Pertence. DJ 26.06.2007; AI 636814 DF. Rel. Min. Eros Grau. DJ 22.05.2007; RE 272839 MT. Rel. Min. Gilmar Mendes. DJ 01.02.2005; RE 238453 SC. Rel. Min. Moreira Alves. DJ 12.11.2002. (BRASIL,2017)
} 
justiça são alcançados, sob essa ótica, o meio-termo poderia também ser utilizado como forma de prejudicar o direito do cidadão. A questão econômica é o principal fator que impossibilita a reparação do Estado em todas as hipóteses.

A ponderação deve ser feita sem perder o foco nos direitos fundamentais. $O$ equilíbrio no orçamento público deve incluir as indenizações e diminuir gastos desnecessários, por exemplo, evitar: centro de compras no Congresso Nacional, publicidade/propaganda dos Entes federados e outras vantagens financeiras que só devem ser consideradas quando os demais direitos, mais importantes, forem assegurados.

A situação de risco criado é utilizada como forma de justificar a responsabilidade do Estado nos casos em que ele cria circunstâncias de risco para os cidadãos. O risco criado ou suscitado pode derivar da situação de guarda de alunos, presos, idosos e pacientes, também pode surgir da guarda de objetos. Nos ambientes geridos pelo Governo a responsabilidade é asseverada. Alunos ${ }^{10}, \operatorname{presos}^{11}$ e outros sujeitos, desde que submetidos a situação de risco pela ação da Administração Pública, são resguardados.

Na sistemática do risco criado a justificativa para a responsabilização do Estado está diretamente ligada à causalidade interna do evento. Eventos tipicamente externos, por exemplo, a queda de raio, não causaria responsabilização do Estado. No caso da causalidade interna, a circunstância criada pelo Estado elevaria o risco do problema em si, por exemplo a briga de crianças na escola pública. As situações logicamente decorrentes do risco causado, chamadas de extensão da custódia, também são de responsabilidade do Estado. Dessa maneira, a fuga de detento e o imediato cometimento de crime gera a responsabilização. Cabe ressaltar que a condição de custódia deve ser determinante para o acontecimento. ${ }^{12}$

Mesmo observando a sistemática do risco criado, a jurisprudência constitucional tem rechaçado a ideia de responsabilidade ligada ao risco integral. A desconsideração de causas que poderiam quebrar o nexo de causalidade traria, segundo a doutrina, um risco sem precedente, conforme já comentado. Olvidam-se que a própria Constituição já delimitou as

\footnotetext{
${ }^{10}$ Jurisprudência "alunos em escolas públicas, risco criado": RE 577.231. Rel. Min. Cármen Lúcia. DJ 15.06.2009; RE 109.615. Rel. Min. Celso de Mello. DJ 2.8.1996; RTF 2816406. Rel. Min. Cármen Lúcia DJ 07.06.2010; (BRASIL, 2017)

${ }^{11}$ Jurisprudência "detentos, risco criado": AI 577.908-8 GO. Rel. Min. Gilmar Mendes. DJ 30.09.2008; RE 466.322 MT. Rel. Min. Eros Grau; RE 215.981 RJ. Rel. Min. Néri da Silveira; AI 299.125 SP. Rel. Min. Celso de Melo; RE 841526. Min. Relator Luiz Fux. DJ 30.03.2016. (BRASIL, 2017)

${ }^{12}$ Decisão "extensão da custódia, derivação do risco criado": AI 463531 RS. Rel. Min. Ellen Gracie. DJ 29.09.2009. (BRASIL, 2017)
} 
possibilidades de responsabilização, por isso, ir além, ou aquém da determinação é inconstitucional, por mais que a as decisões perpetuem essa prática.

\subsection{Risco integral}

O risco integral ${ }^{13}$ é retratado como ponto extremo da responsabilidade civil do Estado. Por esse motivo, o risco integral não é opção para o Supremo Tribunal Federal, de acordo com os julgados apontados em nota. (ARAGÃO, 2013)

No entanto, o risco integral parece ser a alternativa que se coaduna melhor ao que foi previsto na Constituição. Mesmo assim, é visivelmente inviável a admissão de tal raciocínio no Estado brasileiro pela imensa dificuldade na efetivação da responsabilização com fundamento no risco integral. Não obstante o Estado deve se empenhar para transcender essas dificuldades e se colocar definitivamente na condição de responsável nos termos da Constituição. Evitar gastos desnecessários é forma coerente de começar os trabalhos de efetivação da garantia constitucional de responsabilidade objetiva do Estado.

A justificativa do risco integral é baseada na ampliação do princípio da igualdade dos ônus e encargos sociais. A sociedade compartilha suas dificuldades e arcam financeiramente com o prejuízo do semelhante. Todos seriam responsáveis por todos no contexto paradigmático. (CAHALI, 2012)

A regra que prevalece na jurisprudência constitucional é a do risco administrativo. $O$ risco integral é evitado sob a alegação de impossibilidade prática do Estado em relação a arcar com os prejuízos da vida cotidiana do cidadão. Para viabilizar a responsabilidade do Estado seria necessário admitir as excludentes ${ }^{14}$ de responsabilidade o que evitaria abusos no tratamento desse instituto em face da própria sociedade.

Cabe salientar que a doutrina do risco integral nunca foi admitida no Ordenamento Jurídico do Brasil. Durante sua análise, o autor Meirelles (2010) adverte que ela poderia levar a situação de abuso de direito e a iniquidade social.

Apesar de ser a opção que mais se adequa às premissas da responsabilidade objetiva, o risco integral demanda maturidade social que os governos e a sociedade ainda não

\footnotetext{
${ }^{13}$ Jurisprudência "não adoção do risco integral": ADI 4976 DF. Rel. Min. Ricardo Lewandowski. DJ 07.05.2014; RE 238453 SC. Rel. Min. Moreira Alves. DJ 12.11.2002; RE 78569 PR. Rel. Min. Firmino Paz. DJ 15.09.1981; RE 91376 SC. Rel. Min. Xavier de Albuquerque. DJ 28.08.1979; (BRASIL, 2017)

${ }^{14}$ Decisão "excludente por estrito cumprimento do dever legal e legitima defesa": RE 74554 PR. Rel. Min. Rodrigues Alckmin. DJ 30.08.1974. (BRASIL, 2017)
} 
refletiram. Decorrem do risco integral, implicação não só financeira, mas também de relação do Estado com o particular de maneira harmônica e honesta. Esse tipo de responsabilidade poderia interferir na vida dos cidadãos de maneira indesejada, tendo em vista que todos pagariam por um dano que o Estado não deveria suportar, e também poderia condicionar o Estado ao litígio eterno. Assim, a mudança social exigida para admitir o risco integral é profunda. Aspectos como a mediação, a educação do cidadão e o comprometimento da Administração Pública, são fundamentais para essa transformação.

Saber se a adoção do risco administrativo ao invés do risco integral não é derivada apenas do pensamento de preservação do status quo do Estado é algo importante, mas difícil de concluir. Falar que o risco integral nunca foi ou será admitido pelo Estado, como pondera Meirelles (2010) é inviável. Para visualizar a aplicação basta recorrer ao Ordenamento Jurídico e as hipóteses em que a jurisprudência e a doutrina aceitaram a ocorrência da responsabilização objetiva pelo risco integral. São exemplos:

O dano nuclear art. 21 da Constituição da República de 1988 "a responsabilidade civil por danos nucleares independe da existência de culpa". (BRASIL, 1988). Dentre as decisões do Supremo Tribunal Federal, sublinha-se o voto do Min. Ricardo Lewandowski, na Ação Direta de Inconstitucionalidade 4.976, de 07.05.2014. O Ministro relembra a existência da responsabilidade por risco integral no tocante ao dano nuclear, que é amplamente defendido na doutrina.

A responsabilidade por dano ambiental foi tratada pela Lei $\mathrm{n}^{\circ} 6.938,31.08 .1981$ como prescindível de culpa. Posteriormente, o julgado do Superior Tribunal de Justiça abordou a temática do risco integral nesses casos no Recurso Especial (RE) 13.737.88 SP.

Art. $14 \$ 1^{\circ}$ Sem obstar a aplicação das penalidades previstas neste artigo, é o poluidor obrigado, independentemente da existência de culpa, a indenizar ou reparar os danos causados ao meio ambiente e a terceiros, afetados por sua atividade. $\mathrm{O}$ Ministério Público da União e dos Estados terá legitimidade para propor ação de responsabilidade civil e criminal, por danos causados ao meio ambiente. (BRASIL, 1981)

Como sugere Baracho Júnior (2000) o risco integral, em especial para o dano ambiental, advém da intangibilidade das causas de excludente de responsabilidade. A ponderação traz consequências mais rígidas para o autor do dano, sendo essa a resposta à displicência em relação ao meio ambiente que se observa no Brasil.

A assunção de responsabilidade pela União nos casos de atentados terroristas ou atos de guerra contra aeronaves é descrita na Lei $\mathrm{n}^{\circ} 10.309$ 12.11.2001. A referida lei traz a 
sistemática do risco integral para o Ordenamento Jurídico dizendo:

Art. $1^{\circ}$ Fica a União autorizada a assumir as responsabilidades civis perante terceiros no caso de danos a bens e pessoas no solo, provocados por atentados terroristas ou atos de guerra contra aeronaves de empresas aéreas brasileiras no Brasil ou no exterior. (BRASIL, 2001)

A responsabilidade objetiva por risco integral é assunto que permeia a jurisprudência constitucional, seja para a aplicação em alguns casos, seja como paradigma para basilar o risco administrativo. Por certo, a evolução da responsabilidade do Estado não está completa e dependerá da movimentação da sociedade e da situação fática para que seja ponderada a sua efetiva aplicação. Novos casos possuirão valor emblemático com o novo modelo de precedentes trazido pelo Código de Processo Civil de 2015, a jurisprudência constitucional servirá de instrumento para evitar decisões divergentes no Judiciário.

\section{A OMISSÃO E A CONSTITUIÇÃO DE 1988}

A Constituição de 1988 foi fruto da preocupação popular em ter seus direitos resguardados em face do Estado. Foram associados direitos e garantias fundamentais com diversos comandos de ação para o Estado. Surge então a difícil tarefa de compatibilizar os gastos públicos e a efetivação de direitos para o povo. Com muitos deveres e pouco engajamento dos políticos brasileiros, a falta de prestação das obrigações do Estado virou doença estrutural. A Constituição não cumprida gera a chamada omissão estatal e o cidadão permanece impotente para agir contra a lentidão e inação do Estado.

Várias promessas e pouca ação. O verbete é corolário da omissão do Estado frente às determinações constitucionais. Assim, a omissão do Estado pode ser sentida em várias situações. A má conservação de estradas, o descaso médico público, a falta de fiscalização e outras proposições podem dar ensejo a omissão. As várias possibilidades de verificar a omissão do Estado estão ligadas diretamente a benevolência constitucional do povo para o povo. Dessa maneira, é prudente lembrar que a omissão, quando lesiva aos direitos de qualquer pessoa, induz à responsabilidade civil objetiva do Estado, desde que presentes os pressupostos primários, fato, nexo e dano, que lhe determinam a obrigação de indenizar os prejuízos que os seus agentes públicos, nessa condição, hajam causado a terceiros.

Dentre as decisões, sublinha-se o RE 179147 que tem como relator o Min. Carlos Velloso. Os julgadores adotaram a teoria subjetiva da responsabilidade civil do Estado em 
decorrência de fato ou ato omissivo. Seja por negligência, imperícia ou imprudência, o autor da ação deve demonstrar que a conduta omissiva foi resultado de uma inação genérica atribuída ao serviço público. (BRASIL, 1997)

Outras decisões que trabalham a responsabilidade extracontratual por omissão do Estado levam em consideração o aspecto objetivo do Direito. O tema vem se desenvolvendo no Supremo Tribunal Federal, que ultimamente adota a teoria objetiva para os casos de omissão. Consagram critérios objetivos para definir quando o Estado está omisso ou não, com o intuito de nortear as decisões das instâncias inferiores.

Registre-se que atualmente a adoção do risco administrativo ${ }^{15}$ é preponderante. Sublinhe-se o RE 677139 PR cujo relator foi o Min. Gilmar Mendes, julgamento, dia 22.10.2015. Na ementa do respectivo recurso, salienta o julgador que a responsabilidade do Estado se dá pela teoria do risco administrativo mesmo que por omissão. Sendo pressuposto a demonstração de conduta, do dano e do nexo entre eles. (BRASIL, 2015)

\section{A RESERVA Do POSSÍvel E A BASE DA RESPONSABILIDADE CIVIL EXTRACONTRATUAL}

De acordo com Mendes (1999), a reflexão sobre a reserva do financeiramente possível surgiu na Corte Constitucional alemã. Seu pressuposto é condicionar o exercício de um direito previsto legalmente à disponibilidade financeira do Estado.

Atualmente, a reserva do possível é vista com ressalvas na jurisprudência constitucional. Apesar de utilizada, o Supremo Tribunal Federal é relutante em admitir a reserva do possível sem a fundamentação adequada e que não perpasse ou deixe transparecer a irresponsabilidade do Estado. De acordo com os julgados ${ }^{16}$, a reserva do possível não poderia ser utilizada para comprometer o núcleo básico do direito em análise. A omissão estatal não pode comprometer e frustrar direitos previstos na Constituição. O Estado deve ser responsabilizado pelo descumprimento de seus deveres, sendo vedado a ele dar apenas um

\footnotetext{
${ }^{15}$ Jurisprudência "teoria objetiva de responsabilidade quando por omissão": RE 677139 PR. Rel. Min. Gilmar Mendes. DJ 22.10.2015; ARE 847116 RJ. Rel. Min. Luiz Fux. DJ 24.02.2015; AI 852237 RS. Rel. Min. Celso de Mello. DJ 25.06.2013; AI 734689 DF. Rel. Min. Celso de Mello. DJ 26.06.2012; (BRASIL, 2017)

${ }^{16}$ Jurisprudência "aplicação da reserva do possível": ARE 855476 MG Rel. Min. Dias Toffoli. DJ 16.02.2016; STA 223 PE. Rel. Min. Ellen Gracie. DJ 14.04.2008; ARE 745745 MG Rel. Min. Celso de Mello. DJ 02.12.2014; ARE 727864 PR. Rel. Min. Celso de Mello. DJ 04.11.2014; AI 598212 PR. Rel. Min. Celso de Mello. DJ 25.03.2014; ARE 855762 RJ. Rel. Min. Gilmar Mendes. DJ 19.05.2015. (BRASIL, 2017)
} 
parâmetro financeiro para o seu não cumprimento.

A responsabilidade do Estado não pode ser limitada pela reserva do possível na medida em que é garantia constitucional para defesa do cidadão. O complexo arranjo econômico para sustentar prestação digna para a população, resvala no descaso corrupto com que alguns governantes administram o Estado. Coadunar com o erro estatal em casos de descumprimento de ordens constitucionais não pode ser atitude do Poder Judiciário, para isso existe o instituto da responsabilidade.

Estruturar a responsabilidade extracontratual do Estado no parâmetro filosófico contemporâneo é possível nos ensinamentos de Habermas, citado por Baracho Júnior (2000). Depreende-se que a nova visão de Estado de Direito depende da inserção da sociedade como o principal norte para o desenvolvimento do Ordenamento Jurídico.

A divisão dos encargos e prejuízos é alicerce para a responsabilidade civil do Estado, essa estrutura é decorrência lógica da vontade do homem de viver na sociedade. A aceitação do instituto é racional e está associada à construção do processo democrático social de cada nação. Supera-se a ideia de castas sociais defendidas e a validade da norma fica mais próxima da virtude democrática. A validade do art. 37 §6, da Constituição da República de 1988, está no valor que a sociedade atribui a ele, assim, a construção da norma e sua aplicação devem estar intimamente ligadas a ação comunicativa. A função de integração social do direito fica então associada não apenas à norma, mas ao consenso e a convenção do cidadão.

Afastar-se dessa premissa filosófica habermasiana, pela confusão de decisões e pela modificação casuística da responsabilidade civil, demonstra a predominância da vontade do Estado sobre a vontade social. A soberania popular é o que justifica e limita a responsabilização do Estado e não o montante financeiro despendido para a reparação. A racionalidade estruturada e condizente com a vontade do povo é o rumo decisório que a jurisprudência constitucional deve adotar, para que o Estado não seja dominante em relação ao povo, mas coerente com sua vontade.

\section{CONCLUSÃO}

Em face do que foi exposto nos itens precedentes, encaminha-se para a conclusão relativa à problemática da responsabilidade extracontratual do Estado nos seguintes termos: a culpa relaciona-se diretamente a conduta humana, sendo inviável afirmar-se que ela guarda 
relação com a pessoa jurídica. A sociedade conquistou a responsabilização do Estado e com a evolução do instituto, chegou-se à responsabilidade objetiva do Estado desde a Constituição de 1946. Atualmente ela é consagrada no art. 37 § $6^{\circ}$ da Constituição da República de 1988 e no art. 43 do Código Civil de 2002. Entretanto, a doutrina e a jurisprudência, majoritariamente entendem que nos casos de dano resultante de conduta omissiva da Administração ou pelos órgãos responsáveis pelas duas outras funções estatais (Legislativa e Judiciária), o Estado responde subjetivamente.

A hipótese de inexistência de unicidade de entendimento em relação à teoria da responsabilidade civil do Estado se confirmou, com o exame de diversos julgados dos tribunais pátrios, em especial o STF. A variação das decisões é problemática por si só quando o órgão julgador não leva em consideração critérios claros e precisos. Dessa forma, todos os argumentos seriam possíveis e ao mesmo tempo inseguros. O cidadão precisa que seu direito de indenização por parte do Estado seja claro e preciso. Isso significa que qualquer manobra para elidir o direito a indenização em face do Estado é forma de diminuir as garantias constitucionais e dificultar o acesso da população aos direitos fundamentais.

Por fim, a utilização de critérios subjetivos na verificação de responsabilidade do Estado por suas ações, se mostram inapropriadas, tendo em vista a vulnerabilidade do cidadão e a dificuldade de produzir provas da ação ou omissão estatal. Assim, a ponderação sobre o risco administrativo ou integral é a saída para adequar a responsabilidade objetiva nos parâmetros constitucionais, facilitando o acesso do cidadão à indenização. A investigação sobre o tema abordado não se encerra com este despretensioso trabalho, principalmente porque a sociedade continua em plena evolução e cada vez mais consciente e participativa, por meio de audiência pública, consulta pública, orçamento participativo, iniciativa de lei e de emenda constitucional, referendo, plebiscito e por meio das redes sociais. Este último tem sido o meio mais eficiente e ágil que se valem os diversos segmentos da sociedade para levarem seus pleitos propositivos o de protestos aos órgãos instituídos.

\section{REFERÊNCIAS}

ARAGÃO, Alexandre Santos de. Curso de direito administrativo. 2. ed. Rio de Janeiro: Forense, 2013. 
BARACHO JÚNIOR, José Alfredo de Oliveira. Responsabilidade por dano ao meio ambiente. Belo Horizonte: Del Rey, 2000.

BRASIL. Constituição Política do Império do Brasil: DOM PEDRO PRIMEIRO, POR (...). SENIB, Rio de Janeiro, 1824. Disponível em: 〈goo.gl/YxHUzA〉. Acesso em: 19 jul. 2016.

BRASIL. Lei nº 6.938, de 31 agosto de 1981. Dispõe sobre a Política (...). Diário Oficial da União, Brasília , 1981. Disponivel em: <goo.g1/IK6UYH>. Acesso em: 3 jun. 2016.

BRASIL. Constituição da República Federativa do Brasil: Nós, representantes do povo (...). Diário Oficial da União, Brasília, 1988. Disponível em: <goo.gl/WxfQW6>. Acesso em: 5 mai. 2016.

BRASIL. Lei no 10.309, de 22 de novembro de 2001. Dispõe sobre a assunção pela União de responsabilidades civis perante terceiros (...). Diário Oficial da União, Brasília, 2001. Disponivel em: 〈goo.gl/EJVhLi>. Acesso em: 3 jun. 2016.

BRASIL. Lei n ${ }^{\circ} 10.406$, de 10 de janeiro de 2002. Institui o Código Civil. Diário Oficial da União, Brasília, 2001. Disponivel em: <goo.gl/EJVhLi>. Acesso em: 3 jun. 2016.

BRASIL. Supremo Tirbunal Federal. Pleno: Estado tem responsabilidade sobre morte de detento em prisão. Canal Oficial do STF. Brasília: YouTube, 2016b. Disponivel em: <goo.gl/155awl>. Acesso em: 03 jun. 2016.

BRASIL. Supremo Tribunal Federal. RE 179147. Rel. Min. Carlos Velosso. DJ. 12.12.1997. Diário de Justiça Eletrônico, 1997. Disponivel em: 〈goo.gl/guWxBb〉. Acesso em: 09 jun. 2016.

BRASIL. Supremo Tribunal Federal. RE 603626 MS. Rel. Min. Celso de Mello, DJ 15/05/2012. Diário de Justiça Eletrônico, Brasília, 2012. Disponivel em: 〈goo.gl/s68Jyj〉. Acesso em: 02 jun. 2016.

BRASIL. Supremo Tribunal Federal. Pesquisa de jurisprudência. Diário de Justiça Eletrônico. Brasília, 2017. Disponível em:<goo.gl/MsxPRm>. Acesso em: 20 abr 2017.

BRASIL. Supremo Tribunal Federal. Recurso Extraordinário 677139 PR Rel. Min. Gilmar Mendes, julgamento dia 22.10.2015. Diário de Justiça Eletrônico, Brasília, 2015.

Disponivel em: 〈goo.gl/coMCVp〉. Acesso em: 10 jun. 2016.

CAHALI, Yussef Said. Responsabilidade civil do Estado. 4. ed. São Paulo: Revista dos Tribunais, 2012.

CAVALCANTI, Amaro. Responsabilidade civil do Estado. Rio de Janeiro: Borsoi, 1956.

CLARK, Giovanni; CARVALHO, A. R. W.; SOUZA, S. L. S. E. A responsabilidade civil do Estado por Intervenção no domínio econômico. In: FARIA, Edimur Ferreira de (Org.).

Responsabilidade civil do Estado no ordenamento jurídico e na jurisprudencias atuais. Belo Horizonte: Del Rey, 2014.

COUCEIRO, Júlio César da Silveira. Princípio da separação de poderes em corrente tripartite. Rio Grande: Revista âmbito Jurídico, 2016. Disponivel em: 〈goo.g1/pSBUIx>. Acesso em: 27 mai. 2016. 
DALARI, Dalmi de Abreu. Elementos de teoria geral do Estado. 2. ed. São Paulo: Saraiva, 1998.

DI PIETRO, Maria Sylvia Zanella. Direito administrativo. 27. ed. São Paulo: Atlas, 2014.

DIAS, Ronaldo Brêtas de Carvalho. Responsabilidade do Estado pela função jurisdicional. Belo Horizonte: Del Rey, 2004.

ESTEVES, Júlio César dos Santos. Responsabilidade civil do Estado por ato Legislativo. Belo Horizonte: Del Rey, 2003.

FARIA, Edimur Ferreira de. Curso de direito administrativo positivo. 8. ed. Belo Horizonte: Fórum, 2015.

GUIMARÃES, Deocleciano Torrieri. Culpa. In: GUIMARÃES, Deocleciano Torrieri.

Dicionário Técnico Jurídico. 12. ed. São Paulo: Rideel, 2009.

HEITOR, Ivone Susana Cortesão. Livro quinto Ordenações Afonsinas. Coimbra: IHTIFLC, 2016. Disponivel em: <goo.gl/XGaqm8>. Acesso em: 1 jun. 2016.

HOBBES, Thomas. Leviatã ou, Matéria, forma e poder de um Estado eclesiástico e civil. Tradução de João Paulo Monteiro e Maria Beatriz Nizza da Silva. São Paulo: DHnet, 2016. Disponivel em: 〈goo.gl/ZbyKHZ〉. Acesso em: 27 maio 2016.

MEIRELLES, Hely Lopes. Direito administrativo brasileiro. 37. ed. São Paulo: Malheiros, 2010 .

MELLO, Celso Antônio Banceira de. Curso de direito administrativo. 32. ed. São Paulo: Malheiros, 2014.

MENDES, Gilmar Ferreira. Os Direitos Fundamentais e seus múltiplos significados na ordem constitucional. Revista Jurídica da Presidencia, Brasília, 1999. Disponivel em:

<goo.gl/rFY3sN>. Acesso em: 9 jun. 2016.

SÃO PAULO. Prefeitura de São Paulo. Precatórios. Secretaria de negócios jurídicos, 2015. Disponivel em: 〈goo.gl/uZHh4c〉. Acesso em: 14 jun. 2016.

NASCIMENTO, Tupinambá Miguel Castro do. Responsabilidade civil do Estado. Rio de Janeiro: Aide, 1995.

RESTREPO, Ricardo Sanín. Teoría crítica constitucional: rescatando la democracia del liberalismo. Quito, Equador: RisperGraf, 2011.

SHEMOT. In: Torah. Estados Unidos da América: Cabad, 2016. Disponivel em: <goo.gl/vIOGcs>. Acesso em: 01 jun. 2016.

SILVA, Carlos Brandão Idelfonso. Objetivação da responsabilidade civil no Direito brasileiro: Verdade ou mito? 2012. 141f. Dissertação (Mestrado) - Programa de PósGraduação em Direito. Pontifícia Universidade Católica de Minas Gerais. Belo Horizonte, 2012. 